\title{
La simbiosis entre la protección del medio ambiente y la protección de la cultura en la jurisprudencia y el derecho positivo español ${ }^{1}$
}

\section{The symbiosis between environmental protection and culture's protection in the Spanish case law and positive law}

Recibido: 29/08/13 Aprobado: 29/10/13

Roberto O. Bustillo Bolado

Doctor en Derecho Universidad de Cantabria Decano de la Facultad de Derecho de la Universidad de Vigo (España)

rbustillo@uvigo.es

\begin{abstract}
«El peligro radica en que nuestro poder para dañar o destruir el medio ambiente $o$ al prójimo, aumenta a mucha mayor velocidad que nuestra sabiduría en el uso de ese poder»

Stephen Hawking
\end{abstract}

\section{RESUMEN}

El presente artículo recoge una investigación que se desenvuelve con la metodología jurídica, con especial sustento en jurisprudencia y el derecho positivo. Se estudia, desde la perspectiva jurídica del derecho español, la existencia de una intersección entre el medio ambiente y la cultura: Ios monumentos y el paisaje; y cómo la simbiosis de los instrumentos jurídicos que protegen ambos sectores pueden combinarse para mejorar la protección de ambos.

\section{PALABRAS CLAVE}

Medio ambiente, cultura, desarrollo sostenible, derecho ambiental.

\section{ABSTRACT}

This article presents a research that develops with legal methodology, with special support in case law and positive law. Is studied from a spanish legal perspective the existence of an intersection between the environment and the culture: the monuments and landscape; and how the symbiosis of the legal instruments that protect both areas can be combined to improve the protection of both.

\section{KEYWORDS}

Environment, culture, sustainable development, environmental law.

1 Comentario de jurisprudencia (artículo de investigación). El presente artículo es un resultado del proyecto de investigación DERTIC, con referencia DER2011-25359, financiado por el Ministerio de Economía y Competitividad del Gobierno de España. 


\section{INTRODUCCIÓN}

\section{Precisiones terminológicas}

De acuerdo con el diccionario de la Real Academia Española (en adelante RAE) simbiosis es una "asociación de individuos animales o vegetales de diferentes especies, sobre todo si los simbiontes sacan provecho de la vida en común", y simbionte es cada "individuo asociado en simbiosis".

Se expondrá a lo largo de este artículo cómo los expuestos conceptos propios de las ciencias naturales sirven perfectamente para, en términos metafóricos, expresar la relación que existe en el ámbito jurídico entre el medio ambiente y la cultura, ámbitos que en la jurisprudencia y en el Derecho positivo español hallan puntos de encuentro donde la confluencia de instrumentos jurídicos de protección diseñados de forma aislada para uno u otro pueden operar conjuntamente y permitir que los simbiontes (el medio ambiente y la cultura) "saquen provecho de la vida en común", consiguiendo gracias a la protección de la cultura salvar de la destrucción entornos medio ambientales, y gracias a la protección de la cultura, preservar para el futuro bienes con interés histórico y cultural.

La idea del medio ambiente tiende con frecuencia a identificarse con la naturaleza no antropizada 0 , al menos, no muy afectada por la acción del ser humano, lo que en términos lingüísticos y científicos supone no una simplificación, sino una reducción equivocada del concepto. De acuerdo con la RAE -en línea con los más asentados planteamientos científicos-, dos son las acepciones de "medio ambiente": "conjunto de circunstancias exteriores de un ser vivo", y "conjunto de circunstancias culturales, económicas y sociales en que vive una persona"; en realidad, en la medida en que las personas somos seres vivos, la segunda definición va incluida en la primera, pero, en todo caso, destacar aquellos elementos que nos singularizan no resulta ocioso, y de ello se hace fiel eco el derecho positivo y la jurisprudencia española.

De entre todos esos elementos que caracterizan $y$ singularizan el medio ambiente en el que se desarrollan los seres humanos (circunstancias naturales, culturales, económicas y sociales), este estudio se centra en las circunstancias culturales, para desarrollar una idea: la constante presencia y consideración de "la cultura" como elemento a valorar y proteger desde la legislación y jurisprudencia española sobre medio ambiente. Se presentará cómo se plasma tal conexión en la jurisprudencia del Tribunal Constitucional sobre el art. 45 de la Constitución Española de 1978 (en adelante, $\mathrm{CE}$ ), en tratados internacionales firmados y ratificados por España, y en la legislación sobre protección del medio ambiente del Estado y de las Comunidades Autónomas (es decir, de las diecisiete entidades territoriales descentralizadas dotadas de poderes legislativo y ejecutivo en las que se estructura el Estado español). A lo largo de todo ese recorrido se irá viendo cómo tal conexión se materializa fundamentalmente en dos conceptos: el paisaje y los monumentos.

\section{LA SIMBIOSIS EN LA JURISPRUDENCIA DEL TRIBUNAL CONSTITUCIONAL.}

La Sentencia del Tribunal Constitucional (en adelante, STC) 102/1995, del 26 de junio, resuelve acumulados una serie de recursos de inconstitucionalidad y conflictos de competencias planteados por nueve Comunidades Autónomas frente al Estado en relación con la Ley estatal 4/1989, del 27 de marzo, de conservación de los espacios naturales, y con varios Reales Decretos en materia medioambiental. En el F.J. $6^{\circ}$ de la citada sentencia, el Tribunal Constitucional define qué debe entenderse por "medio ambiente". Para ello, toma como punto de partida los tradicionales elementos puramente naturales, destacando ya desde el principio que tales elementos no son todos sino sólo "algunos" de los integrantes del concepto:

La Constitución, en su artículo 45, nos brinda algunos de los elementos del medio ambiente, los recursos naturales, aun cuando tampoco los enumere o defina. Es una noción tan vieja como el hombre, dotada de una sugestiva, aparente y falsa sencillez, derivada de su misma objetividad, mientras que el supra concepto en el cual se insertan es un recién llegado, 
complejo y propicio a lo subjetivo, problemático en suma. Sin embargo de lo dicho, hay dos bienes de la naturaleza, el aire o la atmósfera y el agua, cuyo carácter de recurso vital y escaso hemos reconocido (STC 227/1988) con una posición peculiar, en un primer plano. La pesca marítima 0 ciertos minerales fueron ya incluidos en este catálogo de recursos naturales, alguno como el carbón muy ligado al medio ambiente desde la misma actividad de su extracción (SSTC 147/1991 y 25/1989), así como la agricultura de montaña (STC 144/1985). No sólo la fauna, sino también la flora forman parte de este conjunto cuyo soporte físico es el suelo (y el subsuelo) que puede ser visto y regulado desde distintas perspectivas, como la ecológica, la dasocrática o forestal, la hidrológica, la minera 0 extractiva, la cinegética y la urbanística, a título de ejemplo y sin ánimo exhaustivo, que en su dimensión constitucional dan contenido a distintos títulos habilitantes para el reparto de distintas competencias entre el Estado y las Comunidades Autónomas.

$Y$ acto seguido, junto a los elementos naturales descritos, destaca el "paisaje" como parte integrante del medio ambiente, concepto dentro del cual aparecen elementos naturales y culturales:

Por otra parte, ligado a todo lo ya inventariado está el paisaje, noción estética, cuyos ingredientes son naturales -la tierra, la campiña, el valle, la sierra el mar- y culturales, históricos, con una referencia visual, el panorama o la vista, que a finales del pasado siglo obtiene la consideración de recurso, apreciado antes como tal por las aristocracias, generalizado hoy como bien colectivo, democratizado en suma y que, por ello, ha de incorporarse al concepto constitucional del medio ambiente como reflejan muchos de los Estatutos de Autonomía que luego se dirán. En definitiva, la tierra, el suelo, el espacio natural, como Patrimonio de la Humanidad, produce unos rendimientos 0 «rentas», los recursos, que son sus elementos y cuyo conjunto forma un sistema, dentro del cual pueden aislarse intelectualmente, por abstracción, otros subsistemas en disminución gradual, hasta la célula y el átomo.

De inmediato, el Tribunal Constitucional sintetiza todo el expuesto razonamiento en los siguientes términos:
Así, el medio ambiente como objeto de conocimiento desde una perspectiva jurídica, estaría compuesto por los recursos naturales (...). La flora y la fauna, los animales y los vegetales o plantas, los minerales, los tres «reinos» clásicos de la Naturaleza con mayúsculas, en el escenario que suponen el suelo y el agua, el espacio natural. Sin embargo, ya desde su aparición en nuestro ordenamiento jurídico en el año 1916, sin saberlo, se incorporan otros elementos que no son naturaleza sino Historia, Ios monumentos, asi como el paisaje, que no es sólo una realidad objetiva sino un modo de mirar, distinto en cada época y cada cultura.

De esa forma, el Tribunal Constitucional configura desde la perspectiva jurídica una interrelación entre la protección del medio ambiente y la protección de la cultura que responde al siguiente esquema:

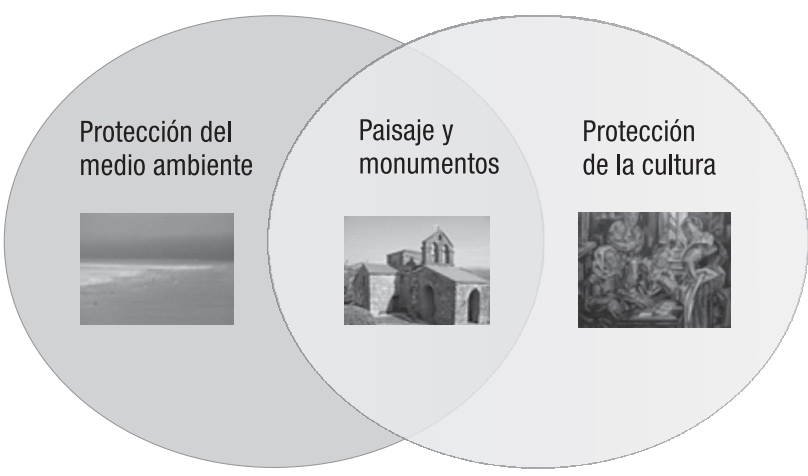

Tal construcción del Tribunal Constitucional ha calado en la jurisprudencia española, y en el mismo sentido de la resolución citada pueden destacarse otras como las sentencias de la Sala Tercera del Tribunal Supremo (en adelante STS) 1520/2007 de 14 de febrero (F.J. $4^{0}$ ), 6894/2008 de 26 de noviembre de 2008 (F.J. 8 ${ }^{\circ}$ ), 7421/2008 de 23 de diciembre (F.J. $7^{\circ}$ ) u 8908/2011 de 14 de diciembre (F.J. $3^{\circ}$ ).

Para terminar con este apartado, basta con señalar que la necesaria conexión entre lo natural y lo cultural a través del paisaje y los monumentos y su consideración conjunta como elementos integrantes del medio ambiente en nuestro Derecho es una construcción del Tribunal Constitucional que no surge de la nada, y que encuentra antecedentes en 
el Derecho Positivo español preexistente. De hecho, antes de la entrada en vigor de la Constitución ya existían normas en el ordenamiento jurídico español en las que se combinaba lo natural y lo cultural a la hora de configurar instrumentos de protección de carácter medioambiental 0 territorial. A título de ejemplo, conviene recordar la regulación en la redacción original de los artículos 13 a 20 de la Ley del Suelo del 12 de mayo de 1956, de los Planes especiales, instrumentos de planeamiento entre cuyos fines se encontraba la "protección del paisaje" (art. 13), y cuyo objeto abarcaba entre otros aspectos "la conservación y valoración del Patrimonio histórico y artístico de la Nación y bellezas naturales" (art. 14.1); no obstante, tal conexión jurídico-urbanística entre lo natural y lo cultural (prolongada hasta la entrada en vigor de la Constitución a través del Texto Refundido de la Ley del Suelo de 1976) no dejaba de ser embrionaria y se basaba en una suma de conceptos que no llegaban a integrarse en uno nuevo, es decir, se contemplaba el "medio natural" y la parte de lo cultural que afectaba al paisaje, pero no se integraba todo ello dentro del concepto "medio ambiente", que es el salto conceptual que se consagra en la comentada STC 102/1995.

Esta idea, como se expondrá de inmediato, es plenamente coherente con la legislación española postconstitucional (tanto estatal como autonómica) y con los convenios internacionales ratificados por España y vigentes a la fecha.

\section{LA SIMBIOSIS EN LOS CONVENIOS INTERNACIONALES SOBRE PROTECCIÓN DEL PAISAJE Y DEL MEDIO AMBIENTE FIRMADOS Y RATIFICADOS POR ESPAÑA.}

La preocupación internacional por el paisaje tiene su carta fundacional en la Conferencia de la Casa Blanca en Washington en 1965, donde se propone potenciar la protección internacional de "zonas naturales y paisajísticas maravillosas del mundo y los sitios históricos para el presente y para el futuro de toda la humanidad". Tras sumarse a la iniciativa la Unión Internacional para la Conservación de la Naturaleza en 1968, tales impulsos acabaron plasmándose en el seno de la UNESCO en la Convención sobre la Protección del Patrimonio Mundial Cultural y Natural, aprobada en París el 16 de noviembre de 1972, ratificada por España diez años más tarde.

Aunque la Convención regula y protege en principio por separado el patrimonio cultural (art. 1) y el natural (art. 2), ya aparecen necesariamente conectados los conceptos de cultura y naturaleza. Así, por ejemplo, una de las categorías de protección cultural son los "lugares", que, de acuerdo con el art. 1 son "obras del hombre u obras conjuntas del hombre y la naturaleza...". Tomando ese concepto mixto como punto de partida, en el año 2008 se aprobaron las Directrices Prácticas para la aplicación de la Convención del Patrimonio Mundial, en cuyo artículo II.A (§§ 46 y 47) se definen el "Patrimonio mixto natural y cultural" y los "Paisajes culturales":

Serán considerados patrimonio mixto cultural y natural bienes que respondan parcial 0 totalmente a las definiciones de patrimonio cultural y patrimonio natural que figuran en los Artículos 1 y 2 de la Convención.

Los paisajes culturales son bienes culturales y representan las obras conjuntas del hombre y la naturaleza citadas en el Artículo 1 de la Convención. llustran la evolución de la sociedad humana y sus asentamientos a lo largo del tiempo, condicionados por las limitaciones $y / 0$ oportunidades físicas que presenta su entorno natural y por las sucesivas fuerzas sociales, económicas y culturales, tanto externas como internas.

El paraguas protector del Convenio no se proyecta en abstracto sobre todo el territorio de los Estados miembros, sino sólo sobre aquellos bienes concretos (edificios, espacios...) que hayan sido previamente identificados y delimitados como merecedores de tal protección. Esta característica determina que las definiciones y principios del Convenio de París de 1972 se agoten en los límites de tales concretos bienes, y que su incorporación al Derecho positivo español no haya supuesto jurisprudencialmente un cambio en principios, conceptos o construcciones de 
carácter general. Es decir, la ratificación por España de dicho instrumento internacional en 1982 marca un antes y un después en cuanto a la protección de los concretos bienes sobre los que se decida proyectar la eficacia del Convenio, pero a efectos prácticos su incidencia sobre la jurisprudencia fue escasa.

Distinto es el caso del Convenio Europeo del Paisaje. El 20 de octubre de 2000, dieciocho Estados miembros del Consejo de Europa (entre ellos España) firmaron en Florencia el Convenio Europeo sobre el Paisaje. Para que el convenio comenzara a desplegar efectos era necesario reunir posteriormente la ratificación de al menos diez Estados signatarios, lo que tuvo lugar el 1 de marzo de 2004. En la actualidad, la mayoría de los estados integrantes del Consejo de Europa lo han firmado y más de la mitad lo han ratificado, entre ellos España mediante instrumento de 6 de noviembre de 2007. Tras publicarse oficialmente en España el instrumento de ratificación en el Boletín Oficial del Estado (en adelante, BOE) de 5 de febrero de 2008, el convenio entró en vigor en España el 1 de marzo de ese mismo año.

Este Convenio supone la primera vez que un documento jurídico de ámbito internacional, los conceptos "patrimonio cultural" y patrimonio natural" se funden en una visión integral del paisaje europeo (con carácter general, proyectándose sobre todo el territorio y no sólo sobre concretos bienes que se delimiten, a diferencia de la ya citada Convención de París de 1972), que forma así un concepto integrado por elementos naturales y antrópicos que puede y debe ser recogido por las leyes generales (valgan como ejemplo las normas más recientes que se citan en el siguiente apartado) y por la jurisprudencia (entre otras, las SSTS de la sala tercera 3852/2013 de 9 de julio, 0 592/2011 de 11 de febrero). Ello se avanza ya con claridad desde su preámbulo:

Tomando nota de que el paisaje desempeña un papel importante de interés general en los campos cultural, ecológico, medioambiental y social (...) Conscientes de que el paisaje contribuye a la formación de las culturas locales y que es un componente fundamental del patrimonio natural y cultural europeo.
La relación entre lo natural y cultural que avanza el preámbulo se materializa a lo largo del articulado en contenidos preceptivos para los Estados que lo incorporen a su Derecho interno. Así, por ejemplo, la expuesta conexión aparece en las definiciones del art. 1:

Art. 1.a por "paisaje" se entenderá cualquier parte del territorio tal como la percibe la población, cuyo carácter sea el resultado de la acción y la interacción de factores naturales y/o humanos.

Art. 1.d por "protección de los paisajes" se entenderán las acciones encaminadas a conservar y mantener los aspectos significativos o característicos de un paisaje, justificados por su valor patrimonial derivado de su configuración natural y/o la acción del hombre.

Y el art 5.a impele a las partes a comprometerse a "reconocerjurídicamente los paisajes como elemento fundamental del entorno humano, expresión de la diversidad de su patrimonio común cultural y natural y como fundamento de su identidad"

En el mismo sentido que el Convenio Europeo del Paisaje, el Convenio de Aarhus, del 25 de junio de 1998, sobre acceso a la información, la participación del público en la toma de decisiones y el acceso a la justicia en materia de medio ambiente (ratificado por España el 15 de diciembre de 2004, y publicado en el BOE del 16 de febrero de 2005), incluye como "información(es) sobre el medio ambiente" toda información disponible que se refiera a, entre otros aspectos: (art. 2.3.c):

c) el estado de la salud, la seguridad y las condiciones de vida de los seres humanos, así como el estado de los emplazamientos culturales y de las construcciones en la medida en que sean 0 puedan ser alterados por el estado de los elementos del medio ambiente 0 , a través de estos elementos, por los factores, actividades o medidas a que hace referencia la letra b) supra.

\section{LA SIMBIOSIS EN LA NORMATIVA SOBRE PROTECCIÓN MEDIO AMBIENTAL COMUNITARIA, ESTATAL Y AUTONÓMICA.}

La citada conexión cultura-naturaleza, como ya se ha avanzado, no es una construcción jurisprudencial 
que el Tribunal Constitucional edifique a mediados de los años noventa a partir de la nada, pues tras los ya aludidos antecedentes positivos preconstitucionales, la entrada el 1 de enero de 1986 de España en las entonces denominadas Comunidades Europeas (hoy, Unión Europea) contribuyó a alentar tal conexión.

En aquel momento surge para España el deber de trasponer la Directiva 85/337/CEE del Consejo, de 27 de junio de 1985, relativa a la evaluación de las repercusiones de determinados proyectos públicos y privados sobre el medio ambiente, en cuyo art. 3 se establecía que la evaluación de las repercusiones sobre el medio ambiente identificara, describiera y evaluara los efectos de cada proyecto sobre una serie de factores, entre los que se encontraban el paisaje y el "patrimonio cultural"; y, en el apartado 3 del Anexo III se enumeraban entre los "elementos del medio ambiente que puedan verse afectados" el paisaje y el "patrimonio arquitectural y arqueológico". La trasposición de tal directiva tuvo lugar en España por medio del Real Decreto Legislativo 1302/1986, del 28 de junio, de Evaluación de impacto ambiental, dictado por el Estado en calidad de legislación básica (art. 149.1.23 ${ }^{\mathrm{a}} \mathrm{CE}$ ), y en cuyos arts. 1.1, 2.1.c y apartado 2.c.8 del Anexo III, se imbricaba cultura y medio ambiente, como exigía la normativa comunitaria.

En la actualidad, las citadas normas europea y básica estatal han sido derogadas por nuevos textos positivos que siguen obedeciendo en lo que ahora nos interesa a los mismos principios.

Hoy en día, la norma europea de referencia es la nueva Directiva 2011/92/UE del Parlamento Europeo y del Consejo, de 13 de diciembre de 2011, relativa a la evaluación de las repercusiones de determinados proyectos públicos y privados sobre el medio ambiente, que, con la finalidad de simplificar, refunde en un solo texto la Directiva 1302/1986 con las tres modificaciones a que fue sometida en 1997, 2003 y 2009.

En España, el viejo Real Decreto Legislativo 1302/1986 y sus múltiples modificaciones fueron refundidas en un único texto por el R.D. Legislativo
1/2008, del 11 de enero, por el que se aprueba el texto refundido de la Ley de Evaluación de Impacto Ambiental de proyectos. El citado Real Decreto Legislativo 1/2008 constituye, por tanto, en la actualidad, la legislación básica estatal en la materia, y contiene las pertinentes conexiones entre medio ambiente y cultura en los arts. 1.3. c, 2.7, 7.1.c y en el apartado 2.c.8 del Anexo III. Baste a título de ejemplo con recordar el contenido del citado art. 7.1.c del R.D. Legislativo 1/2008, que al regular el contenido de los estudios de impacto ambiental incluye entre ellos la:

Evaluación de los efectos previsibles directos 0 indirectos del proyecto sobre la población, la flora, la fauna, el suelo, el aire, el agua, los factores climáticos, el paisaje y los bienes materiales, incluido el patrimonio histórico-artístico y el arqueológico.

En la misma línea de las leyes estatales citadas, el art. 2.2.a del Real Decreto Legislativo 2/2008, Texto Refundido de la Ley del Suelo, establece que en virtud del principio de desarrollo sostenible, las políticas públicas del suelo procurarán (apartado este no modificado por la Disp. Final $12^{\mathrm{a}}$ de la Ley $8 / 2013$, de 26 de junio, de rehabilitación, regeneración y renovación urbanas): "a) La eficacia de las medidas de conservación y mejora de la naturaleza, la flora y la fauna y de la protección del patrimonio cultural y del paisaje".

Todo lo expuesto (jurisprudencia constitucional, convenios internacionales ratificados por España, normativa de la Unión Europea y legislación estatal de eficacia básica o plena) tiene su correspondiente reflejo en las legislaciones de las Comunidades Autónomas. Sinánimoni necesidad de ser exhaustivo, basten como ilustración las conexiones entre medio ambiente y cultura contenidas en los arts. 11.2.g, 12.3.g, 13.2.f y 23 de la Ley canaria 11/1990, del 13 de julio, de prevención del impacto ecológico; los arts. 17 y 28.2.d de la Ley de Cantabria 17/2006, del 11 de diciembre, de Control Ambiental Integrado; los arts. 16.1.h 0 28.1.h de la Ley 2/2002, del 19 de junio, de Evaluación ambiental de la Comunidad de Madrid; el art. 83.c de la Ley de la Región de Murcia 4/2009, del 14 de mayo, de Protección ambiental 
integrada; 0, por último, véase el art. 4 de la Ley 1/1995, del 2 de enero, de protección del medio ambiente de Galicia, de donde con facilidad puede deducirse una buena definición legal del concepto "medio ambiente":

Art. 4.- Ámbito de protección: A los efectos de la presente Ley, se considera que son elementos que tienen que protegerse: el medio natural constituido por la población, la fauna, la flora, la diversidad genética, el suelo, el subsuelo, el agua, el aire, el clima y el paisaje, así como la interrelación entre los elementos antes mencionados, los recursos naturales y culturales, incluido el patrimonio arquitectónico y arqueológico, en cuanto pueden ser objeto de contaminación y deterioro por causas ambientales.

\section{UN SUPUESTO CONCRETO DE RESULTADOS DE LA SIMBIOSIS ENTRE LA PROTECCIÓN DEL MEDIO AMBIENTE Y LA PROTECCIÓN DE LA CULTURA: EL CASO DE LA STS DEL 15 DE OCTUBRE DE 2010.}

En varias ocasiones, la Sala Tercera del Tribunal Supremo ha tenido que, en términos de desarrollo sostenible, ponderar intereses contrapuestos entre el desarrollo económico y la conservación del medio, considerando en el lado de la balanza de la conservación de medios valores naturales, sociales y culturales. Ejemplo paradigmático lo constituye la STS (Sala tercera) 5190/2010 del 15 de octubre, que desestima el recurso de casación interpuesto contra la Sentencia de la Sala Segunda del Tribunal Superior de Justicia de Galicia (en adelante, STSJGalicia) del 5 de diciembre de 2007. El asunto era el siguiente.

La empresa Cuarzos Industriales S.A. era titular de una concesión para explotar un yacimiento de cuarzo sobre una extensión de unas 200 hectáreas en el término municipal lucense de Palas de Rei. El art. 105.1 de la Ley 22/1973, del 21 de julio, de Minas, reconoce al titular legal de una concesión de explotación "derecho a la expropiación forzosa u ocupación temporal de los terrenos que sean necesarios", lo que habilita al concesionario para solicitar de la Administración el inicio de un expediente expropiatorio en el que al primero le corresponde el papel de beneficiario. Sin embargo, la empresa se encuentra con una dificultad que afecta a alrededor de un $15 \%$ de la superficie de la concesión (31,5 hectáreas exactamente), y es que tal extensión se corresponde con parte de dos montes vecinales en mano común ("Merlán" y "Hospital"), terrenos que, de acuerdo con la Ley 13/1989, del 10 de octubre, de montes vecinales en mano común de Galicia, "sólo podrán ser objeto de expropiación forzosa (...) por causa de utilidad pública o interés social prevalentes a los de los propios montes vecinales".

Con la intención de salvar tal escollo, Cuarzos Industriales S.A. solicita al Consejero de Medio Ambiente de la Xunta de Galicia (la "Xunta" es el Gobierno de la Comunidad Autónoma de Galicia) que declare la prevalencia de su concesión minera sobre los montes vecinales, a los efectos de que la Administración Autonómica active a continuación el correspondiente procedimiento expropiatorio sobre tales terrenos. Sin embargo, la Consejería de Medio Ambiente, por medio de resolución del 16 de febrero de 2004, desestima la solicitud de la empresa, y, posteriormente, el 1 de julio de 2004, otro tanto sucede con el recurso de reposición interpuesto contra la misma. Cuarzos Industriales S.A. acude en única instancia ante el Tribunal Superior de Justicia de Galicia, quien por Sentencia del 5 de diciembre de 2007, desestima sus pretensiones. La demandante interpone recurso de casación contra la citada sentencia, y el Tribunal Supremo desestima el recurso por medio de la STS de 15 de octubre de 2010 , cuyas líneas maestras en lo que a los efectos de este estudio interesa (recogidas todas ellas en el F.J. $2^{\circ}$ ) paso a exponer de inmediato.

Abordar este conflicto jurídico implica que -como señala el TS en la sentencia comentada- el aplicador de la norma tiene que efectuar "un juicio de contraste sobre los elementos de utilidad pública 0 interés social que han de sobreponerse a los propios de dichos montes vecinales". Es decir, hay que ponderar los intereses en juego (los intereses 
públicos y privados -de Cuarzos Industriales S.A.que representa la concesión minera por un lado, y, por otro, los intereses públicos y privados -de los vecinos de Palas de Rei- que supone la subsistencia como monte vecinal de las 31,5 hectáreas en cuestión), y en tal ponderación juegan un papel fundamental las alegaciones fácticas de las partes, alegaciones fácticas que, salvo en aquellos casos en que lo alegado pueda tener la consideración de "hecho notorio", deben contar para ser eficaces con un adecuado respaldo de prueba.

Planteada la cuestión en los términos descritos, el iterargumental del juicio de contraste o ponderación de intereses que efectúa la sentencia discurre por sucesivas batallas que mantienen la resolución del conflicto en la incertidumbre hasta el final.

$Y$ las cosas no empiezan bien para Cuarzos Industriales S.A. Los demandados le reprochan que no se entiende bien que en el momento presente se quiera obtener una declaración de prevalencia para un título concesional obtenido en los años setenta del siglo XX y que, por tanto, ha estado sin activarse cerca de treinta años. La respuesta de la empresa a tal objeción resulta en principio coherente: alega la actora que la situación del mercado ha cambiado, y que la importancia del cuarzo que puede extraerse de esta explotación hoy es mucho mayor que en el pasado, pues se corre "riesgo de desabastecimiento de materias primas en la industria gallega de ferroaleaciones". Sin embargo, no aporta Cuarzos Industriales S.A. material probatorio alguno que demuestre ni la afirmación del alegado "riesgo de desabastecimiento de la industria gallega", ni que demuestre tampoco que la explotación, precisamente, de las 31,5 hectáreas en cuestión (recuérdese que representa solo cerca de un $15 \%$ del total de la concesión) sea esencial para la actividad extractiva concedida.

Aquí podría haberse terminado sin más el asunto, si no fuera porque la actora aporta un documento administrativo que supone un verdadero torpedo en la línea de flotación de la defensa de los demandados: un informe del Servicio de Montes e
Industrias Forestales "que concluyó que las zonas afectadas carecían de interés ecológico 0 social que justifiquen el mantenimiento de la situación actual".

En consecuencia, atendiendo sólo a elementos socio-económicos y naturales, la cuestión no estaba en absoluto clara, pues Cuarzos Industriales S.A. no había demostrado la importancia para la explotación minera de la expropiación de las 31,5 hectáreas de montes vecinales, pero sí había aportado elementos probatorios que apuntaban hacia el escaso valor ecológico y social de la superficie afectada.

Es en estos momentos cuando la protección de la cultura entra en juego reforzando la protección del medio ambiente e inclinando la balanza de forma decisiva hacia la conservación del medio. Y es que los demandados alegan a favor de la legalidad del acto recurrido:

a) La existencia en esas 31,5 hectáreas de yacimientos arqueológicos.

b) El paso por esos terrenos de una ruta del Camino de Santiago.

De poco sirve a Cuarzos Industriales haber aportado en la instancia un testigo-perito que declarara que los yacimientos arqueológicos en cuestión son de escaso valor, puesto que la Ley 8/1995, de Patrimonio Cultural de Galicia, protege todos los yacimientos arqueológicos, sin distinguir entre importantes y poco importantes 0 valiosos y poco valiosos; y de poco le sirve también manifestar que la explotación minera no va a tener incidencia directa sobre la ruta del Camino de Santiago, pues el Camino de Santiago es algo más que una senda, es un paisaje, un conjunto de elementos, razón por la cual la protección legal no se preocupa sólo de la conservación del itinerario, sino también de su entorno, y así, el art. 16.3.b de la Ley 3/1996, de Protección de los Caminos de Santiago, prohíbe explotaciones mineras. En cuanto a la incidencia sobre el asunto de ambas normas de protección cultural, resume el TS afirmando que: 
Es suficiente para suscitar el interés de la Administración sobre este punto que la intervención sea indirecta comprometiendo el entorno morfológica, visual y acústicamente, y acreditar la propia existencia de yacimientos arqueológicos, con independencia de que fuera susceptibles de protección complementaria. (Art. 8 Ley 8/1995 de Patrimonio Cultural de Galicia y art. 16.3.b de la Ley de Galicia 3/1996 de protección de los Caminos de Santiago).

De esa forma, la consideración de elementos jurídicos de protección de la cultura hizo posible la obtención de un resultado de conservación medioambiental que habría sido incierto considerando sólo elementos ecológicos y sociales.

No obstante, no es necesario llegar a un desenlace que paralice la operación de desarrollo, si la incidencia de la misma sobre los elementos culturales 0 históricos ha sido debidamente detectada en el instrumento de impacto ambiental que resulte pertinente $y$, en consecuencia, se ha previsto la adopción de medidas correctoras dentro del margen de maniobra discrecional, es decir, que resulten razonables, sin perjuicio que desde una perspectiva puramente protectora puedan existir otras opciones de igual calidad 0 incluso mejores. llustrativo en este sentido puede resultar el asunto resuelto en casación por la STS (Sala Tercera) 3184/2012 del 30 de abril de 2012, en relación con el recrecimiento del embalse de "Yesa Río Aragón". La declaración de impacto ambiental (DIA) del proyecto estudiaba dos alternativas (F.J. $11^{\circ}$ ):

La primera, constituir un embalse a una cota máxima de 521 metros, lo que significa una elevación de 32 metros sobre la de 489 metros actual (...) con aumento de inundación de 2097 hectáreas y aumento del volumen de vaso de $1.045 \mathrm{hm}^{3}$.

"La segunda, constituir un embalse con cota máxima de 506 metros, lo que significa una elevación de 17 metros sobre la de 489 metros actual (...), con aumento de inundación de 1.041 hectáreas, y aumento de volumen de vaso de $420 \mathrm{hm}^{3}$.

(...)
LaDIA después de analizar las alternativas propuestas y las distintas afecciones que conllevan una y otra, señala que, con la documentación aportada por el promotor, de las alternativas mencionadas, la consistente en constituir un embalse con COTA máxima de agua a 506 metros es la más favorable para el medio ambiente, si bien es insuficiente para la satisfacción de los objetivos específicos que justifican el proyecto, razón por la que la alternativa viable es la del embalse de COTA máxima de agua de 521 metros.

Los recurrentes (el Ayuntamiento de Artieda y una asociación) alegan -además de otros argumentosque la opción elegida en la DIA (cota 521 metros) resulta ilegal, en la medida en que la afectación de las más de 1.000 nuevas hectáreas respecto de la otra opción menos lesiva supone la inundación de un pequeño núcleo rural (Sigües), de algunos kilómetros del Camino de Santiago y de varias ermitas adyacentes y, además, no se establece medida alguna en caso de que al hilo de las obras se descuban nuevos yacimientos arqueológicos o paleontológicos. El Tribunal Supremo reconoce que el primigenio Estudio de Impacto Ambiental presentaba, efectivamente, carencias en cuanto a la corrección de los efectos sobre el patrimonio cultural, pero tales carencias fueron subsanadas posteriormente de la siguiente manera:

Con posterioridad, como consecuencia de la citada DIA y de los estudios medioambientales realizados, se confeccionó la Addenda 4/1999, donde se recogen una serie de actuaciones medioambientales para recuperar y minimizar los impactos negativos del proyecto.

Así, en el anejo 26 del Proyecto aprobado se contemplada la "Reposición del Camino de Santiago", valorada en la Addenda del Proyecto. El tramo afectado se sitúa entre las localidades de Artieda y Ruesta y para su reposición se ha previsto un camino de $11,155 \mathrm{Km}$. de longitud de trazado paralelo a la carretera e independiente de ella para su utilización por los peregrinos en ese tramo. En ese tramo del Camino afectado por el recrecimiento se sitúan las ermitas de San Jacobo y San Juan de Ruesta, a las que seguidamente nos referiremos. 
En el Anejo 27 del Proyecto "Actuaciones en el Patrimonio Histórico Artístico" valoradas dentro de la Addenda del Proyecto, se contempla el traslado de los elementos del patrimonio histórico del núcleo de Sigües (Iglesia de San Esteban Casa Palacio y Hospital de los Peregrinos de Santa Ana) y el traslado de las dos citadas ermitas que resultan inundadas por el recrecimiento, junto al "Camino de Santiago", contemplándose la restauración de esta última. No se contempla el traslado de las ermitas de San Pedro (Artieda), San Juan Bautista (Sigües) y Virgen de las Viñas (Escó) al estar a cota superior y no resultar afectadas por el recrecimiento, contemplándose la restauración de todas ellas. Por otra parte, en el Anejo 28 "Estudios arqueológicos, etnográficos y paleontológicos", también valorado dentro de la Addenda del Proyecto, se contemplan la realización de prospecciones arqueológicas, etnográficas y paleontológicas, que se realizarán (en cuanto a su estudio, catalogación, reasentamiento etc.), con cumplimiento de las normas procedimentales previstas en la normativa específica, sobre patrimonio cultural y habrán de realizarse durante la ejecución de las obras.

Todos los informes de órganos y organismos públicos existentes en autos entienden suficientes las medidas adoptadas, y así lo entiende también en la instancia la Audiencia Nacional y en casación el Tribunal Supremo, que desestiman sucesivamente las pretensiones de los recurrentes.

La solución jurisprudencial al asunto que se acaba de exponer parece sólidamente cimentada en un contexto de equilibrio de intereses y desarrollo sostenible. No obstante, no son muchos los años que la jurisprudencia española lleva dictando sentencias en las que se efectúan siempre difíciles ponderaciones de intereses en el marco del principio constitucional de desarrollo sostenible, y la novedad de tal principio y el ya expuesto fundamental juego que desempeñan dentro de cada caso la práctica y valoración de la prueba, determina que a priori resulte en la mayoría de los casos aventurado anticipar con una solvencia razonable cual va a ser el sentido de la resolución judicial del conflicto.

\section{CONCLUSIONES}

De todo lo expuesto, pueden deducirse las siguientes conclusiones:

1. Los ámbitos objetivos de aplicación de las normas protectoras del medio ambiente y de las normas protectoras del patrimonio cultural tienen un amplio espacio de coincidencia constituido por el paisaje y los monumentos; tal afirmación cuenta en España con el sólido respaldo de la jurisprudencia del Tribunal Constitucional, de la Sala Tercera del Tribunal Supremo, del Derecho positivo interno (estatal y autonómico), de la Convención para la Protección del Patrimonio Mundial Cultural y Natural y del Convenio Europeo sobre el Paisaje firmado en Florencia el 20 de octubre de 2000.

2. De la combinación en fase administrativa de la acción de instrumentos de uno y otro sector del ordenamiento jurídico (protección del medio ambiente y protección del patrimonio cultural), y de la combinación en fase judicial de los intereses y la sensibilidad propia de ambos, pueden obtenerse buenos resultados tuitivos sobre espacios 0 bienes concretos difíciles 0 imposibles de conseguir en ocasiones con la consideración aislada de lo medioambiental desprovista de elementos culturales, 0 de lo cultural desprovisto de elementos medioambientales; la jurisprudencia española ofrece buenos ejemplos (aunque no del todo uniformes) a lo largo de la última década.

3. Para que la simbiosis entre protección del medio ambiente y protección de la cultura rindiera unos resultados óptimos sería necesario 0 conveniente una mayor interrelación entre los equipos técnicos y políticos que dentro de cada Administración Pública desarrollan tales competencias; tal interrelación podría plasmarse en la institucionalización de cauces de encuentro, intercambio y colaboración entre los distintos equipos especializados 0 , también, en la creación de equipos multidisciplinares. 


\section{REFERENCIAS BIBLIOGRÁFICAS}

- Bustillo Bolado, R. /Gómez Manresa, Ma . F. (2012). "Sustainable Development: a Principle implicitly assumed by the Spanish Constitution", en Electronic Journal of Environmental, Agricultural and Food Chemistry (ISSN 15794377) núm. 11 (5) pgs.: 578-585. Disponible en http://dertic.16mb.com/actividades/

- Fernández de Gatta Sánchez, D. (2012). Sistema jurídico-administrativo de protección del medio ambiente. Salamanca, Editorial Ratio Legis.

- Jaquenod de Zsögön, S. (2011). Manual para el estudio del Derecho Ambiental. Madrid, Editorial Dykinson.
- Lozano Cutanda, B. (2011). Derecho ambiental administrativo $11^{\mathrm{a}}$ Ed. Madrid, Editorial La LeyActualidad.

- Martín Mateo, R. (1991).Tratado de Derecho Ambiental. Madrid, Editorial Trívium.

- Ortega Álvarez, L. Alonso García, C. (2003). Tratado de Derecho Ambiental. Valencia, Editorial Tirant lo Blanch.

- Soriano García, E. (2010/2011). Claves del Derecho Ambiental (2 vols.). Madrid, Editorial lustel.

- Torres López, M. Arana García, E. (2012). Derecho Ambiental. Madrid, Editorial Tecnos. 